This paper has been retracted. A Retraction notice was published on 3 August 2018, in The 1st International Electronic Conference on Crystals, 21-31 May, 2018; Sciforum Electronic Conference Series, Vol. 1, 2018, doi: 10.3390/IECC_2018-05245

\title{
sciforum
}

Conference Proceedings Paper

\section{Tetramer Compound of Manganese Ions with Mixed Valence [MnII Mn2IIIMnIV] and Its Spatial, Electronic, Magnetic, and Theoretical Studies}

\author{
Cándida Pastor Ramírez 1, Sylvain Bernès 2, Rafael Zamorano Ulloa 3 , Daniel Ramírez-Rosales 3, \\ Hugo Vázquez-Lima ${ }^{4}$, Yasmi Reyes-Ortega 1,* and Samuel Hernández-Anzaldo 1,* \\ 1 Centro de Química, Instituto de Ciencias, Universidad Autónoma de Puebla, Edif. IC9, CU, San Manuel, \\ 72570 Puebla, Pue. México \\ 2 Instituto de Física, Universidad Autónoma de Puebla, Edif. 1IF1, CU, Col. San Manuel, 72570 Puebla, Pue., \\ México \\ 3 Departamento de Física, ESFM, IPN, Av. Instituto Politécnico Nacional S/N, Edif. 9, U.P. Zacatenco, Col. \\ San Pedro Zacatenco, 07738 México, DF, México \\ 4 Departamento de Ciencias Naturales, Universidad Autónoma Metropolitana, Campus Cuajimalpa, \\ Avenida Vasco de Quiroga 4871, Santa Fe Cuajimalpa, 05370 Cuajimalpa, CDMX, México \\ * Correspondence: samuel.henadezan@correo.buap.mx (S.H.-A.) yasmi.reyes@correo.buap.mx (Y.R.-O); \\ Tel.: +52-222-2295500-7064
}

Abstract: Using different spectroscopic techniques and computational calculations, we describe the structural and electromagnetic relationship that causes many interesting phenomena within a novel coordination compound with mixed valence Manganese (II, III and IV) in its crystal and powder state. The novel compound was obtained with the Schiff base (E)-2-((2-hydroxybenzylidene)amine)2-(hydroximethyl-propane-1,3-diol, $\left(\mathrm{H}_{4} \mathrm{~L}\right)$ and $\mathrm{Mn}\left(\mathrm{NO}_{3}\right)_{2} .4 \mathrm{H}_{2} \mathrm{O}$. The coordination reaction was promoted by the deprotonation of the ligand by the soft base trimethylamide. The paper's main contribution is the integration of the experimental and computational studies to explain the interesting magnetic behavior that the mixed valence Manganese multimetallic core shows. The results presented herein, which are rarely found for Mn(II), (III) and (IV) complexes, will contribute to the understanding of the magnetic communication generated by the valence electrons and its repercussion in the local geometry and in the overall crystalline structure.

Keywords: Intermolecular and intramolecular interactions; mixed valence; magnetic interactions; coordination geometry

\section{Introduction}

Recently, many types of multimetallic-centered compounds have been extensively studied, notably Manganese coordination compounds, due to their scientific and technological role as magnetoresistive (GMR or CMR) materials, their biological significance as emulators of catalytic domains, and others [1]. Moreover, such complexes exhibit superparamagnetic-like properties as single molecule magnets (SMMs). This type of complexes display slow relaxation of magnetization and function as magnets below the blocking temperature [2]. The time frame for the relaxation of magnetization is thermally controlled by the spin ground state and the equatorial anisotropy, $D$ [3]. 
The 1st International Electronic Conference on Crystals (IECC 2018), 21-31 May 2018;

Sciforum Electronic Conference Series, Vol. 1, 2018

As part of the construction of multi Mn, Co, Cu and Fe [4] complexes with such characteristics, Schiff base ligands acting as brick units has been both widely and successfully used. Interestingly, Schiff base ligands seem to promote the formation of multicenter coordination compounds with mixed valence states due to the diversity of electronegative groups and availability for coordination [5]. On the other hand, several complexes with low nuclearity of Mn ions have been widely studied [6]. The coexistence of $\mathrm{Mn}(\mathrm{II})$ and $\mathrm{Mn}(\mathrm{IV})$ in inorganic complexes has also been demonstrated. These compounds have biological relevance due to the presence of the $\mathrm{Mn}(\mathrm{IV})$ species, which participates in the oxygen-evolving complex that is formed by $4 \mathrm{Mn}$ ions with a mixture of $\mathrm{Mn}$ (III) and Mn(IV), around fifty systems in humans [7,8]. Additionally, the photosynthetic process needs four Manganese ions to perform the bio catalysis, and it has been seen that $\mathrm{Mn}(\mathrm{IV})$ is present during turnover. By these arguments, multi-Manganese-centered coordination compounds represent a great area for coordination researches to direct their attention [9]. In this work we present the synthesis, structure, electronic, magnetic, and theoretical studies of a mixed valence tetramer compound with [Mn(II)$\left.\mathrm{Mn}(\mathrm{III})_{2}-\mathrm{Mn}(\mathrm{IV})\right]$ starting from (E)-2-((2-hydroxybenzylidene)amine)-2-(hydroximethyl-propane-1,3diol, $\left(\mathrm{H}_{4} \mathrm{~L}\right)$, and $\mathrm{Mn}\left(\mathrm{NO}_{3}\right)_{2}$.

\section{Experimental Methods}

\subsection{Equipment and Measurements Conditions}

Electronic spectra were measured with a Beckman DU Series 7000 equipment on ca $10^{-4} \mathrm{M}$ in methanolic solutions at $298 \mathrm{~K}$ at 200-800 nm. A Nicolet Magna-IR 750 spectrophotometer was employed to monitor the infrared spectra, using KBr. ESR spectra at X-band frequency were obtained with a Bruker ELEXSYS E500 II spectrometer from 300 to $80 \mathrm{~K}$ on polycrystalline powder samples. The ESR analysis was performed with the simulation program of WINEPR SimFonia (Bruker). The magnetic $g$-tensor components needed for simulations were obtained from fitting rigid limit $~ 9.4641$ $\mathrm{GHz}$ spectra recorded at $80 \mathrm{~K}$ in a powder sample. The sweep width was calibrated at $7996.00 \mathrm{G}$ with a center field of $3998.0 \mathrm{G}$. We referenced the $\mathrm{g}$ values to the common $g_{x x}$ value of 2.00233 and then accurately determined the $g_{y y}$ and $g_{z z}$ values relative to this $g_{z z}$ value from the corresponding spectral splitting. The A-tensor components were obtained from fitting rigid limit $\sim 9.4641 \mathrm{GHz}$ as well. Magnetic measurements were performed in gelatin capsule using a Physical Property Measurement System (PPMS®) from Quantum Design. Measurements were performed in small magnetic fields, from 20 to $200 \mathrm{G}$, and in the range $2.8-300 \mathrm{~K}$ in zero field-cooling (ZFC). The diffraction equipment of four circles is a Stradivari, STOE, based on an Eulerian geometry goniometer with an angular precision of $0.001^{\circ}$. The X-ray source is a micro-source of AXO, with a silver anode. The monochromator selecting the Ag-K $\alpha$ radiation (wavelength $\lambda=0.56083 \AA$ as a mixture of the radiations $\mathrm{Ag}-\mathrm{K} \alpha_{1}$ and $\left.\mathrm{Ag}-\mathrm{K} \alpha_{2}\right)$ is a double mirror multilayer of elliptical geometry, model Astix-f$110 / 320$ with a divergence $\Delta \Phi<0.03^{\circ}$. The micro-source was energized at $65 \mathrm{kV}$ and $0.60 \mathrm{~mA}$ (power: $39 \mathrm{~W})$ and the beam directed on the glass through a $0.3 \mathrm{~mm}$ aperture collimator. The area detector is a Pilatus-100K of DECTRIS (Baden, Switzerland), counting 94,965 independent pixels (reverse-biased silicon diode array, with a thickness of $1000 \mu \mathrm{m}$ ), each pixel having an area of $0.172 \times 0.172 \mathrm{~mm}^{2}$, and a dynamic measurement range of 20 bits. The diffraction data was collected with the program $X$-Area 1.76 [10]. The PC is accessible by remote access via TeamViewer, and includes all the usual updated crystallochemistry programs: Shelx, Olex2, SIR, Superflip, WinGX, Xprep, MoPro, CSD-Enterprise, GSAS-II, etc. [11]. Elemental composition was obtained by XPS. Samples were analyzed using a Surface Science Instruments SSX-100 with operating pressure $\sim 2 x 10-9$ Torr. Monochromatic Al K $\alpha$ x rays $(1486.6 \mathrm{eV})$ with a $1 \mathrm{~mm}$ diameter beam size were used. Photoelectrons were collected at a $55^{\circ}$ emission angle. A hemispherical analyzer determined electron kinetic energy, using a pass energy of $150 \mathrm{~V}$ for wide/survey scans, and $50 \mathrm{~V}$ for high resolution scans. A flood gun was used for charge neutralization of non-conductive samples. The quantity calculation was performed with CasaXPS software. 
The 1st International Electronic Conference on Crystals (IECC 2018), 21-31 May 2018;

Sciforum Electronic Conference Series, Vol. 1, 2018

\subsection{Computational Details}

All molecular structures were optimized using density functional theory approach with the functional PBE [12] and the basis 6-31g [13] within the constrained symmetry group Ci. All molecules proved to be minima according to frequency calculations with the exception of one model (vide infra). This molecule was optimized one more time without the symmetry constriction and the minimum was achieved. The resulting structures were optimized again with the functional B3LYP [14] and the basis set 6-31g(d) for lighter atoms and LANL2DZ [15] for Mn atoms with its corresponding effective core potentials. After that, single point calculations with the functional B3LYP, the basis set 6-31g+(d) for lighter atoms and LANL2DZ for Mn atoms was completed for all models.

\subsection{Synthesis}

For the synthesis of $\mathbf{1}$, a previously reported methodology was used for similar complexes [16]. $0.4 \mathrm{mmol}$ of the reported organic ligand $\mathrm{H}_{4} \mathrm{~L}$ [17] was dissolved in $5 \mathrm{~mL}$ of methanol at room temperature under magnetic stirring. $2.8 \mathrm{mmol}$ of the soft base trimethylamine was added to promote the deprotonation of the hydroxyl groups present in the ligand and stirred for $0.5 \mathrm{~h}$. Then, $0.04 \mathrm{mmol}$ of $\mathrm{Mn}\left(\mathrm{NO}_{3}\right)_{2} .4 \mathrm{H}_{2} \mathrm{O}$, previously dissolved in in $5 \mathrm{~mL}$ of methanol was added to produce a burgundy colored solution. The final solution was filtered by gravity at room temperature and the residues left for slow evaporation to obtain crystals of 1 suitable for $x$ ray studies with a yield of $85 \%$ and a Dec. Temp. $215^{\circ} \mathrm{C} .1$ is soluble in methanol, ethanol, DMSO and DMF. Spatial group: $P-1, a=10.757(33)$ $\AA, b=11.68793(3) \AA, c=13.328(4) \AA, \alpha=98.72(2)^{\circ}, \beta=110.37(2)^{\circ}, \gamma=108.08(4)^{\circ}, \mathrm{V}=1428.42(7) \AA^{3}$; UV-

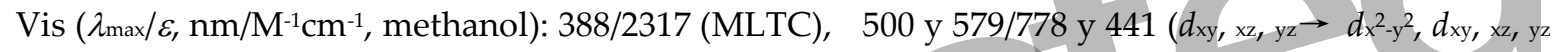
$\left.\rightarrow d_{\mathrm{z}^{2}}\right)$; IR (cm-1, KBr): $3273(\nu \mathrm{o}-\mathrm{H}), 1604(v \mathrm{c}=\mathrm{N}), 1301$ ( $v_{\mathrm{c}-\mathrm{o}),} 447$ (Mn-O); NMR-1H (500 MHz, DMSO-d6, $\delta$, ppm): 17.6, 6.7 - 7.6, 4.1 - 4.7, 2.99,1 - 1.5; ESR (crystalline powder, $300 \mathrm{~K} / 90 \mathrm{~K}$, and in DMSO solution, 90K): $g_{300} / g_{90}=49,306,271 / 48,333,289 ; A=8 \times 10^{4} \mathrm{~cm}^{-1} ; \chi_{M} T_{300 K}=369 \mathrm{~cm}^{3} \mathrm{~mol}^{-}$ ${ }^{1} \mathrm{~K}, \chi_{M} T_{3 K}=446 \mathrm{~cm}^{3} \mathrm{~mol}^{-1} \mathrm{~K}$. Elemental composition by XPS: C: $40.82 \%, \mathrm{H} \mathrm{7.00 \% ,} \mathrm{N} \mathrm{5.38 \% ,} \mathrm{O}$ $30.00 \%$, Mn 16.94\%; Calc. C 40.84\%, H 7.09\%, N 5.41\%, O 29.67\%, Mn $16.98 \%$.

\section{Results and Discussion}

\subsection{Synthesis}

The used methodology gave a mixed-valence tetra-nuclear cluster [ $\mathrm{Mn}^{\mathrm{II}} \mathrm{Mn}^{\mathrm{III}_{2}}$ $\left.\mathrm{Mn}^{\mathrm{IV}}(\mathrm{HL})_{2}\left(\mathrm{H}_{2} \mathrm{~L}\right)_{2}\left(\mathrm{H}_{2} \mathrm{O}\right)_{4}\right]\left(\mathrm{NO}_{3}\right)_{2}$ presenting an oxidation of $\mathrm{Mn}(\mathrm{II})$ to $\mathrm{Mn}(\mathrm{III})$ and $\mathrm{Mn}(\mathrm{IV})$, which were stabilized by different grades of the ligand deprotonation. The redox potential value of the $\mathrm{Mn}^{3+} \mathrm{O}_{2} / \mathrm{Mn}^{2+}$ at $p H=8, E=+1.79 \mathrm{~V}$ with $\Delta G=-173.28 \mathrm{~kJ} \mathrm{~mol}{ }^{-1}$, for $\mathrm{Mn}^{4+} \mathrm{O}_{2} / \mathrm{Mn}^{2+}$ at $p H=8, E=+0.99 \mathrm{~V}$ with $\Delta G=-191.81 \mathrm{~kJ} \mathrm{~mol}^{-1}$, both spontaneous processes. This oxidation process of $\mathrm{Mn}(\mathrm{II})$ was observed by changes in coloration from orange to burgundy. During the establishment of the synthetic methodology, the effect obtained by using different concentrations of base was studied, looking for a larger number of Manganese ions in the cluster. We concluded that this parameter it not affected by the $\mathrm{O}-\mathrm{H}$ ligand deprotonation. Notably, the temperature, reaction time, and stoichiometric reactants relation were varied one parameter in each assay, and $\mathbf{1}$ was always obtained.

\subsection{Structural Analysis}

A burgundy rectangular crystal of 1 was resolved by x ray crystallography, showing a triclinic cell with spatial group $P-1$. Table 1 summarizes the crystallographic data. Figure 1 shows the structure of $\mathbf{1}$ which is a center-symmetric tetramer of Manganese ions with mixture valences (II), (III) and (IV). In Table 2 the bonds length and angles of interest are summarized. 
The 1st International Electronic Conference on Crystals (IECC 2018), 21-31 May 2018;

Sciforum Electronic Conference Series, Vol. 1, 2018

Table 1. Crystallographic refinement data of $\mathbf{1}$.

\begin{tabular}{ll}
\hline Empirical Formula & $\mathrm{C}_{44} \mathrm{H}_{60} \mathrm{Mn}_{4} \mathrm{~N}_{6} \mathrm{O}_{27}$ \\
\hline Formula weight & 1324.74 \\
\hline Crystalline system & Triclinic \\
\hline Spatial group & $P-1$ \\
\hline $\boldsymbol{a}=\mathbf{1 0 . 7 5 7 ( 3 )} \AA$ & $=98.72(2)^{\circ}$ \\
\hline $\boldsymbol{b}=\mathbf{1 1 . 6 8 7 ( 3 )} \AA$ & $=110.37(2)^{\circ}$ \\
\hline $\boldsymbol{c}=\mathbf{1 3 . 3 2 8 ( 4 )} \AA$ & $=108.08(2)^{\circ}$ \\
\hline Volume & $1428.4(7) \AA^{3}$ \\
\hline R-factor (\%) & $\mathrm{R}=12.43$ \\
\hline
\end{tabular}

In Figure 1 the basic nucleus of the crystallographic structure which denotes all $\mathrm{Mn}$ (III) ions according to crystallographic distances (see Computational Details) is shown. Figure 1 shows a primary nucleus $\left[\mathrm{Mn}(\mathrm{III}) \mathrm{e}^{\prime}\left(\mathrm{H}_{2} \mathrm{~L}\right)[\mathrm{Mn}(\mathrm{II}) \mathrm{i}(\mathrm{HL})]_{2} \mathrm{Mn}(\mathrm{IV}) \mathrm{e}^{\prime}\left(\mathrm{H}_{2} \mathrm{~L}\right)\right]$. This molecular nucleus contains four units of $\left[\mathrm{Mn} \mu_{5}-\mathrm{O}, \mu_{1}-\mathrm{N}\right]$ where each Manganese ion is bonded to four ligands through one phenolic oxygen atom, to two phenolato oxygen atoms, which connect it to other Manganese ion neighbor, and to the nitrogen atom of the imino group, which connects a Manganese ion with the next Manganese ion. One of the four six-coordinated Manganese ions, Mn2, is coordinated to one-donor atom of $\mathrm{HL}^{3-}$ ligands and to two donor atoms of $\mathrm{HL}^{2-}$ ligands, displaying bond lengths between 1.8752.161 $\AA$. Mn1 ions are coordinated to four-donor atom of two HL2- ligands, showing the Mn1 bond lengths for Mn2 this range is between 1.852-2.305 $\AA$ (Table 2). Nevertheless, the structure of 1 shows an inversion center which would be able to produce the unity [Mn(II), Mn(IV)- $\mu-\mathrm{O}-\mathrm{N}]$, but the degree of deprotonation of the ligand under the $\mathrm{pH}$ conditions of the reaction produces the unity [Mn(II), $\left.[\mathrm{Mn}(\mathrm{III})]_{2}, \mathrm{Mn}(\mathrm{IV})-\mu-\mathrm{O}-\mathrm{N}\right]$. The unit cell contains two nitrate counter ions (-2), four OH groups $(-4)$, $\operatorname{six} \mu-\mathrm{O}(-6)$, four $\mu-\mathrm{N}$ and two waters for each Mn 4 unity. Each Manganese ion is coordinated by five oxygen and one nitrogen atoms, producing an octahedral ligand field with axial elongation with bond lengths $>2.15 \AA$, with respect to the bond equatorial distances $<1.997 \AA$ [18]. The oxygen atoms axially coordinated to the Mn1 ion correspond to $-\mathrm{OH}$ group of the ligand (O22\#1, Mn1-O2\#1); for $\mathrm{Mn} 2$ these axially coordinated oxygen atoms belong to two water molecules (O26, O25) (Figure 1).

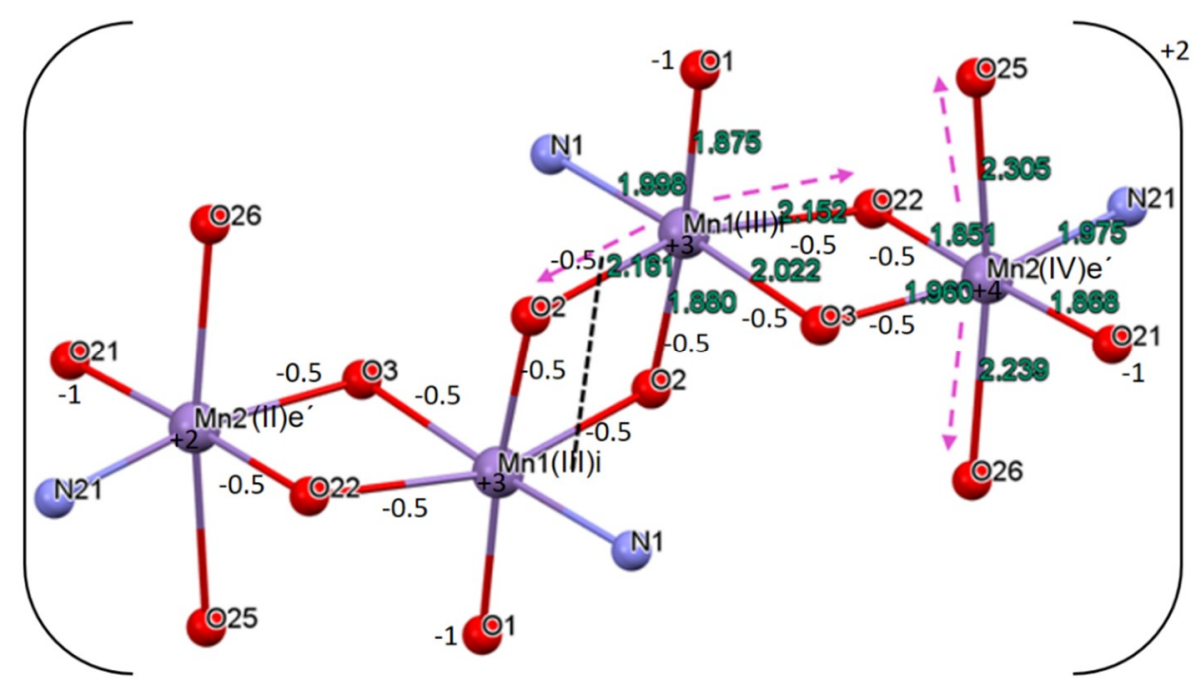

Figure 1. Molecular structure of $\mathbf{1}$. Hydrogens have been omitted for clarity. Label's code: e' outer $\mathrm{Mn}(\mathrm{IV})$, i intern $\mathrm{Mn}(\mathrm{II})$, and $\mathrm{e}^{\prime}$ outer $\mathrm{Mn}(\mathrm{III})$. Oxidation states were proposed from the reaction conditions, the structure formal charges, the IR, UV-Vis, ESR studies and theoretical calculations. The 
The 1st International Electronic Conference on Crystals (IECC 2018), 21-31 May 2018;

Sciforum Electronic Conference Series, Vol. 1, 2018

overall charge of the Manganese ions is +12 and they are neutralized by -10 charges of the $\mathrm{O}$ and $\mu$ $\mathrm{O}$; since there are two $\mathrm{NO}_{3}{ }^{-}$anions, which would be balanced by one on each outer Manganese ions, and then the inversion center, is feasible. Nevertheless, it is possible to observe Manganese ions (III), (II) and (IV) by spectroscopic measurements.

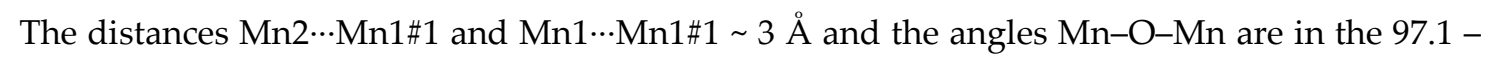
$100.8^{\circ}$ interval. These structural characteristics are in accordance with literature suggesting that the $\mathrm{Mn} 1$ has an oxidation state of +3 , while that of the Mn2 would be +2 and +4 [19]. The oxidation states assigned to the Manganese ions based on the structural characteristics were reinforced by the ESR studies, discussed in the corresponding section. Although, the theoretical optimization of the structure and the ESR results, presented in their respective section, suggest oxidation states of $+2,+3$ and +4 (Figure 1 ).

Table 2. Bond length $[\AA]$ and angles $\left[{ }^{\circ}\right]$ of $\mathbf{1}$.

\begin{tabular}{|c|c|c|c|}
\hline Mn1-O1 & $1.875(10)$ & $\mathrm{O} 2-\mathrm{Mn} 1-\mathrm{O} 22 \# 1$ & $89.6(4)$ \\
\hline Mn1-O2 & $1.880(10)$ & $\mathrm{N} 1-\mathrm{Mn} 1-\mathrm{O} 22 \# 1$ & $103.7(4)$ \\
\hline Mn1-N1 & $1.997(11)$ & O3\#1-Mn1-O22\#1 & $75.0(4)$ \\
\hline Mn1-O3\#1 & $2.023(9)$ & $\mathrm{O} 1-\mathrm{Mn} 1-\mathrm{O} 2 \# 1$ & $95.4(4)$ \\
\hline Mn1-O22\#1 & $2.152(9)$ & $\mathrm{O} 2-\mathrm{Mn} 1-\mathrm{O} 2 \# 1$ & $82.9(4)$ \\
\hline Mn1-O2\#1 & $2.161(10)$ & $\mathrm{N} 1-\mathrm{Mn} 1-\mathrm{O} 2 \# 1$ & $93.4(4)$ \\
\hline Mn1-Mn1\#1 & $3.036(5)$ & $\mathrm{O} 3 \# 1-\mathrm{Mn} 1-\mathrm{O} 2 \# 1$ & $87.2(4)$ \\
\hline Mn1-Mn2\#1 & $3.068(3)$ & $\mathrm{O} 22 \# 1-\mathrm{Mn} 1-\mathrm{O} 2 \# 1$ & $160.3(3)$ \\
\hline Mn2-O22 & $1.852(9)$ & $\mathrm{O} 22-\mathrm{Mn} 2-\mathrm{O} 21$ & $176.5(4)$ \\
\hline Mn2-O21 & $1.868(10)$ & $\mathrm{O} 22-\mathrm{Mn} 2-\mathrm{O} 3$ & $83.6(4)$ \\
\hline Mn2-O3 & $1.960(9)$ & $\mathrm{O} 21-\mathrm{Mn} 2-\mathrm{O} 3$ & $99.8(4)$ \\
\hline Mn2-N21 & $1.976(12)$ & $\mathrm{O} 22-\mathrm{Mn} 2-\mathrm{N} 21$ & $83.1(5)$ \\
\hline Mn2-O26 & $2.240(11)$ & $\mathrm{O} 21-\mathrm{Mn} 2-\mathrm{N} 21$ & $93.5(5)$ \\
\hline Mn2-O25 & $2.305(12)$ & O3-Mn2-N21 & $166.6(4)$ \\
\hline Mn1-O2-Mn1\#1 & $97.1(4)$ & $\mathrm{O} 22-\mathrm{Mn} 2-\mathrm{O} 26$ & $89.9(4)$ \\
\hline Mn2-O3-Mn1\#1 & $100.8(5)$ & $\mathrm{O} 21-\mathrm{Mn} 2-\mathrm{O} 26$ & $90.0(5)$ \\
\hline Mn2-O22-Mn1\#1 & $99.8(4)$ & $\mathrm{O} 3-\mathrm{Mn} 2-\mathrm{O} 26$ & $85.5(4)$ \\
\hline O1-Mn1-O2 & $174.3(4)$ & N21-Mn2-O26 & $96.5(5)$ \\
\hline O1-Mn1-N1 & $92.1(4)$ & $\mathrm{O} 22-\mathrm{Mn} 2-\mathrm{O} 25$ & $90.0(4)$ \\
\hline O2-Mn1-N1 & $82.6(4)$ & $\mathrm{O} 21-\mathrm{Mn} 2-\mathrm{O} 25$ & $90.6(5)$ \\
\hline O1-Mn1-O3\#1 & $92.5(4)$ & $\mathrm{O} 3-\mathrm{Mn} 2-\mathrm{O} 25$ & $85.9(4)$ \\
\hline O2-Mn1-O3\#1 & $92.8(4)$ & N21-Mn2-O25 & $92.1(5)$ \\
\hline N1-Mn1-O3\#1 & $175.3(5)$ & $\mathrm{O} 26-\mathrm{Mn} 2-\mathrm{O} 25$ & $171.3(4)$ \\
\hline O1-Mn1-O22\#1 & $93.8(4)$ & $\mathrm{O} 2-\mathrm{Mn} 1-\mathrm{O} 22 \# 1$ & $89.6(4)$ \\
\hline
\end{tabular}

Symmetry transformation to produce equivalent atoms: $\# 1-x+1,-y+2,-z+1$. 


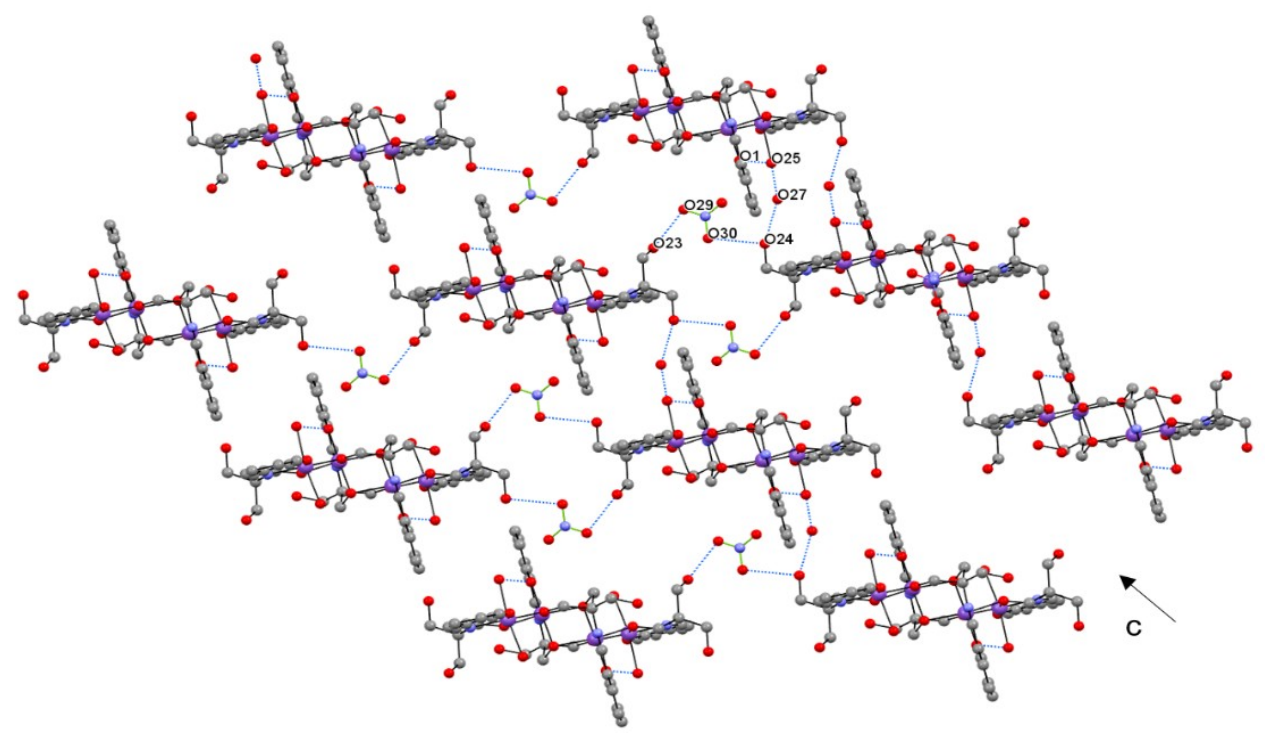

Figure 2. Zig-zag supramolecular patter in the structure of $\mathbf{1}$ by hydrogen bridges along $c$ axis.

Intermolecular hydrogen bridges build a 2D supramolecular structure (Figure 2). Each Manganese ion in $\mathbf{1}$ is coordinated to five oxygen atoms and one nitrogen atom, with an axially distorted octahedral geometry. This last statement is observed for the axial distances which are longer than the equatorial distances (Table 2) [20]. The deviation of Mn2, with respect to the plane formed by the $\mathrm{O} 21, \mathrm{~N} 21, \mathrm{O} 22$ and $\mathrm{O} 3$ atoms is of $0.013 \AA$, and for Mn2 the deviation from the plane formed for the $\mathrm{O} 3, \mathrm{O} 22, \mathrm{O} 2$ and $\mathrm{N} 1$ is of $0.125 \AA$. The angles for an octahedral perfect geometry would be of $90^{\circ}$ in plane and $180^{\circ}$ between the axial positions. Although for $\mathbf{1}$ these angle values are different, Álvarez et al [21] have proposed equation 1 to calculate a distortion from $O_{\mathrm{h}}$ symmetry to a $D_{4 \mathrm{~h}}$ symmetry.

$$
S\left(O_{h}\right)=5.39 \cdot \Delta^{2}-0.33 \cdot|\Delta|=0.96
$$

where $\Delta=$ longer distance-shorter distance, taking the $S\left(O_{h}\right)$ a value $>0$ for octahedral elongation and a value $S\left(O_{h}\right)<0$ for a tetragonal distortion, this parameter takes a value $=0$ for a perfect octahedron. For Mn1 the $S\left(O_{h}\right)=034$ and for Mn2 the $S\left(O_{h}\right)=096$. These results are consistent with the oxidation states proposed for Mn1 of 3+, 4+ and Mn2 of 2+, showing a major distortion towards D4h symmetry for Mn1(IV) [16,22].

\subsection{Absorption Spectra}

Table 3. UV-Vis data of $\mathbf{1}$, with the oscillator strength value, $f$.

\begin{tabular}{|c|c|c|c|}
\hline Transition & $\lambda_{\max }(\mathrm{nm}) / \varepsilon\left(\mathrm{M}^{-1} \mathrm{~cm}^{-1}\right)$ & $\operatorname{Energy}\left(\mathrm{cm}^{-1}\right)$ & $F\left(\mathbf{M}^{-1} \mathbf{c m}^{-1}\right)$ \\
\hline$\pi \rightarrow \pi^{*}$ & $211 / 6143$ & 47396 & 0.086 \\
\hline$\pi \rightarrow \pi^{*}$ & $237 / 5086$ & 42196 & 0.059 \\
\hline$n \rightarrow \pi^{*}$ & $269 / 2561$ & 37177 & 0.015 \\
\hline$L C T \rightarrow M$ & $388 / 2317$ & 25841 & 0.0123 \\
\hline$d-d$ & $500 / 778$ & 20965 & 0.00139 \\
\hline$d-d$ & $579 / 441$ & 19158 & 0.00045 \\
\hline
\end{tabular}

UV-Vis spectroscopy was performed in methanol at room temperature for complex $\mathbf{1}$. Within the whole curve of the spectrum we were able to solve different transitions by calculating Gaussian deconvolutions [23] of the whole spectrum resulting in $2 d$-d forbidden transitions between $\lambda_{\max }=$ $400-579 \mathrm{~nm}$. These values fall into the axially distorted octahedral geometry and belong to the 
The 1st International Electronic Conference on Crystals (IECC 2018), 21-31 May 2018;

Sciforum Electronic Conference Series, Vol. 1, 2018

$d_{x y x z y z} \rightarrow d_{x^{2}-y^{2}}\left({ }^{4} A_{2} \rightarrow{ }^{4} T_{2}\right)$ y $\quad d_{x y x z y z} \rightarrow d_{z^{2}}\left({ }^{4} A_{2} \rightarrow{ }^{4} T_{1}\right)$ transitions [24]. Additionally, the electronic transition energies were in accordance with the presence of a $\mathrm{Mn}^{4+}$, which was confirmed by the IR and ESR experiments and computational calculations. Finally, a high energy MLCT was observed at $388 \mathrm{~nm}$ confirming the Manganese ions coordination with the organic ligand (Table 3).

\subsection{Infrared Spectroscopy}

The IR analysis of $\mathbf{1}$ was made at room temperature using $\mathrm{KBr}$ pellets as a matrix to hold the sample. Comparison of $\mathrm{H}_{4} \mathrm{~L}$ and $\mathbf{1}$ shows two main changes, in the $\mathrm{O}-\mathrm{H}$ and $\mathrm{C}=\mathrm{N}$ vibrations that are shifted to lower energies when coordinated to the ionic metals Mn(II), (III) and (IV). The lack of electrons in the oxidized form of Mn ions makes them highly electronegative (Table 4), affecting the vibration energy by its requirement of electron density from the surrounding atoms. However, the more interesting changes are present at the low energy zone from 1200 to $1500 \mathrm{~cm}^{-1}$. The structure of 1 resolved by x-ray crystallography and the computationally optimized chemical structure, shown in their corresponding sections, imply a lattice built by hydrogen bonds which affects the C-O frequencies of the phenolato groups in the theoretical IR spectrum, making the assignation of vibration bands of the experimental spectrum possible (Figure 1).

Table 4. Values of vibrations of $\mathrm{C}-\mathrm{O}$ groups coordinate to Manganese ions obtained experimentally and by theory calculations of $\mathbf{1}$.

\begin{tabular}{llllll}
\hline \multirow{4}{*}{ Compound } & $\mathrm{C}-\mathrm{O}$ & $\mathrm{C}-\mathrm{O}$ & & & \\
& $\mathrm{Mn}(\mathrm{III}) \mathrm{e}^{\prime}$ & $\mathrm{C}-\mathrm{O}$ & $\mathrm{C}-\mathrm{O}$ \\
& $\mathrm{Mn}(\mathrm{II}) \mathrm{i}$ & $\begin{array}{l}\mathrm{Mn}(\mathrm{II}) \mathrm{i} \\
\mathrm{Mn}\end{array}$ & $\mathrm{Mn}(\mathrm{II}) \mathrm{i}$ & $\mathrm{Mn}(\mathrm{IV}) \mathrm{e}$ Mn(II)i & Mn-N and/or Mn-O \\
& & & & \\
\hline 1-experimental & 1384 & 1338.59 & 1305.87 & 1290.37 & $447 / 1.45$ \\
1-theoretical calculations & 1370 & 1340 & 1306 & 1295 & \\
\hline
\end{tabular}

i, internal Manganese central ions; e, outer Manganese external ions.

The mixed-valence $\mathrm{Mn}$ ion complexes have been studied deeply by various spectroscopies [25]. Many of these reports disregarded the changes in the vibrational information promoted by the differences in the oxidation states. We integrated computational results to the experimental IR spectrum to ensure the assignment of phenolic C-O bond stretching mode (Figure 3). By deconvolution of the experimental vibration bands, it was possible to identify several bands that are in accordance with the theoretical estimation of four vibrational energies for C-O bonds (Figure 3).

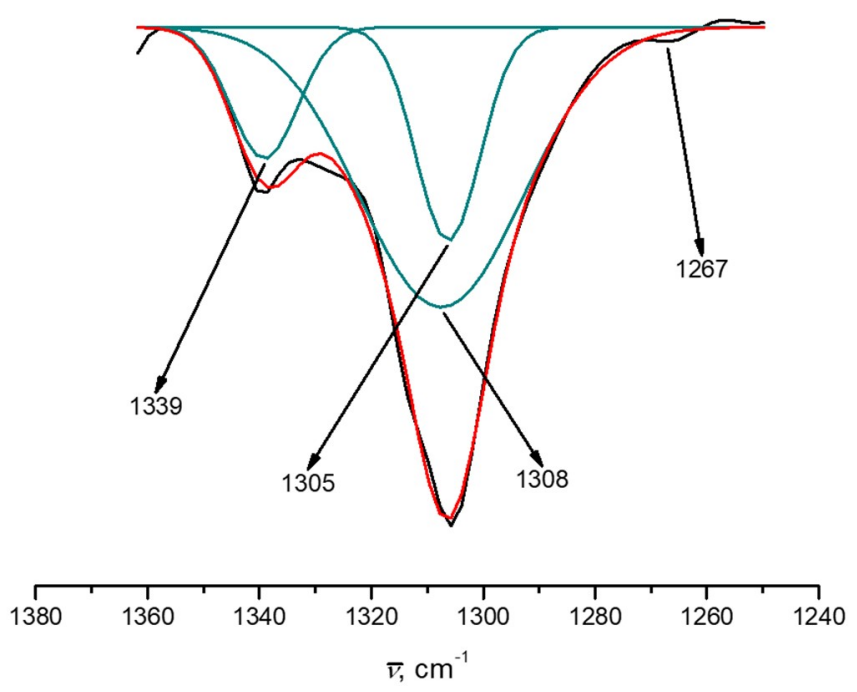

Figure 3. Experimental IR spectrum of 1 with a zoom of C-O vibration adjusted with Gaussians. 
The 1st International Electronic Conference on Crystals (IECC 2018), 21-31 May 2018;

Sciforum Electronic Conference Series, Vol. 1, 2018

\subsection{Proton Nuclear Magnetic Resonance}

Analyzing paramagnetic compounds by NMR spectroscopy is always a difficult task due to the various phenomena that involve the electron spin momentum interactions with the nuclei, resulting in a distorted base line in the spectrum, making it almost unassignable [26]. In our case, the $\mathrm{H}_{4} \mathrm{~L}$ NMR-1 spectrum changes drastically when coordinated to $\mathrm{Mn}(\mathrm{II})$, (III), (IV). According to the crystal structure, four molecules of $\mathrm{H}_{4} \mathrm{~L}$ are coordinated with four Manganese ions. The bond distances Mn-Haromatic are $5.46 \AA$ on average. Thus, all aromatic protons are more distant from the influence of the metallic ions, provoking a loss of the structural symmetry and making them magnetically non-equivalent [27]. Moreover, the multiplicity of the isotropic chemical shifts is also modified with respect to the free ligand, and the signals are shifted to higher energies due to the electronegativity of the metallic ions, as shown in Figure 4.

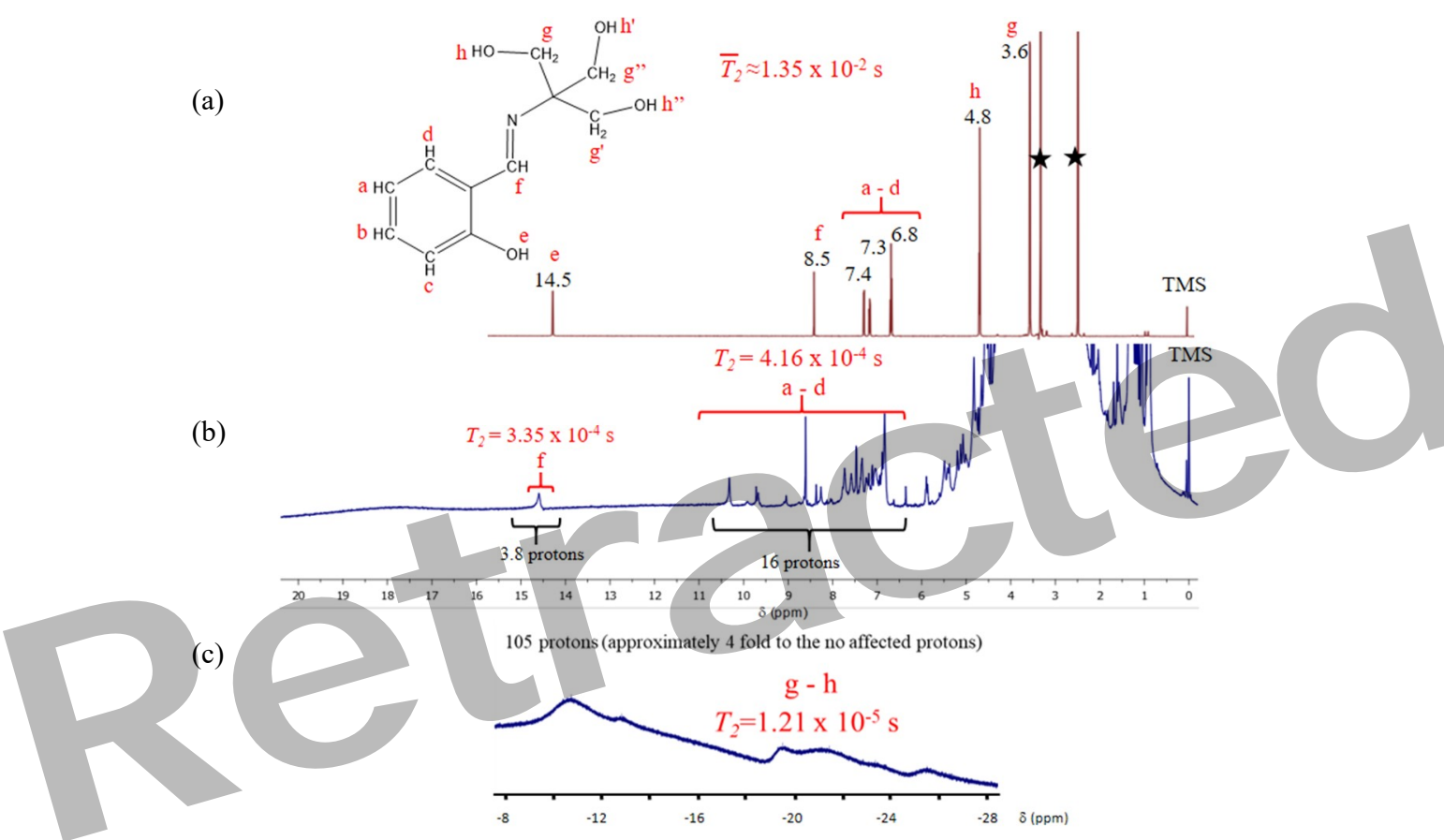

Figure 4. (a) ${ }^{1} \mathrm{H}-\mathrm{NMR}$ of $\mathrm{H}_{4} \mathrm{~L}$ with proton assignments of the chemical shifts and relaxation times. (b) Typical ${ }^{1} \mathrm{H}-\mathrm{NMR}$ for a paramagnetic compound showing magnetic anisotropy and shorter relaxation times (two and up to three-fold higher) generated by the Manganese ions coordinated to the $\mathrm{H}_{4} \mathrm{~L}$ ligands. (c) Isotropic chemical shifts in the negative chemical displacement zone of the spectrum.

The estimation of the integrals for the 16 protons farther from the paramagnetic aromatic center in the molecule was performed in the area between 6 to 11 ppm. Additionally, the signal at 15 ppm (Figure $4 b$ ) was assigned to the proton in the H-CN group, with a difference of displacement from the free $\mathrm{H}_{4} \mathrm{~L}$ of $6.4 \mathrm{ppm}$. The estimated integral of 4 is in agreement with the number of this type of protons in the whole molecule, and the distance from the Manganese is of $3.78 \AA$. Finally, the most affected protons belong to the methyl and hydroxyl groups, which are the closer to the magnetic center with bond distances of $3.5 \AA$ and $4.7 \AA$, respectively, and appearing now at negative displacement in a range from -11 to $-30 \mathrm{ppm}$. The high electronegativity of the Manganese ions withdraws electronic density from the covalent M-L bonds. This group of signals have a broad shape, characteristic of rapid relaxation times due to the highly effective relaxation mechanism induced by the spin-spin interactions [28]. 
The 1st International Electronic Conference on Crystals (IECC 2018), 21-31 May 2018;

Sciforum Electronic Conference Series, Vol. 1, 2018

Table 5. Widthlines of the chemical shifts, relaxation times, and average distances between Manganese ions and protons for $\mathrm{H}_{4} \mathrm{~L}$ (blue lines) and $\mathbf{1}$ (white lines).

\begin{tabular}{cccc}
\hline Protons & Widthline $(\mathrm{ppm})$ & $T_{2}(\mathrm{sec})$ & Average distance to $\mathrm{Mn}^{\mathrm{n}+}(\AA)$ \\
\hline $\mathrm{H}_{4} \mathrm{~L} \mathrm{O}-\mathrm{H}$ & 0.4 & $1.35 \times 10^{-2}$ & $\mathrm{n} / \mathrm{a}$ \\
$\mathrm{H}_{4} \mathrm{~L}$ aromatic & 0.3 & $1.35 \times 10^{-2}$ & $\mathrm{n} / \mathrm{a}$ \\
$\mathrm{H}_{4} \mathrm{~L} \mathrm{C}=\mathrm{N}$ and C-H & 0.1 & $2.25 \times 10^{-2}$ & $\mathrm{n} / \mathrm{a}$ \\
$\mathbf{1}, \mathrm{H}^{+}$aromatic & 1.5 & $4.16 \times 10^{-4}$ & 5.50 \\
$\mathbf{1}, \mathrm{H}^{+}$of the C=N & 1.2 & $3.35 \times 10^{-4}$ & 3.78 \\
$\mathbf{1}$ aliphatic C-H & 3 & $1.21 \times 10^{-5}$ & 3.06 \\
\hline
\end{tabular}

The energy range covered by the signal can be used to calculate the real values of the transverse relaxation time [29]. The $T_{2}$ parameter, which is ruled mainly by the spin-spin mechanism, is heavily affected by the presence of the Manganese ions and its effect on the signal depends of its closeness to the nuclei [30]. A summary of the protons' relaxation times and its dependence to the distance to the metallic ion can be seen in Table 5 .

\subsection{Electron Spin Resonance}

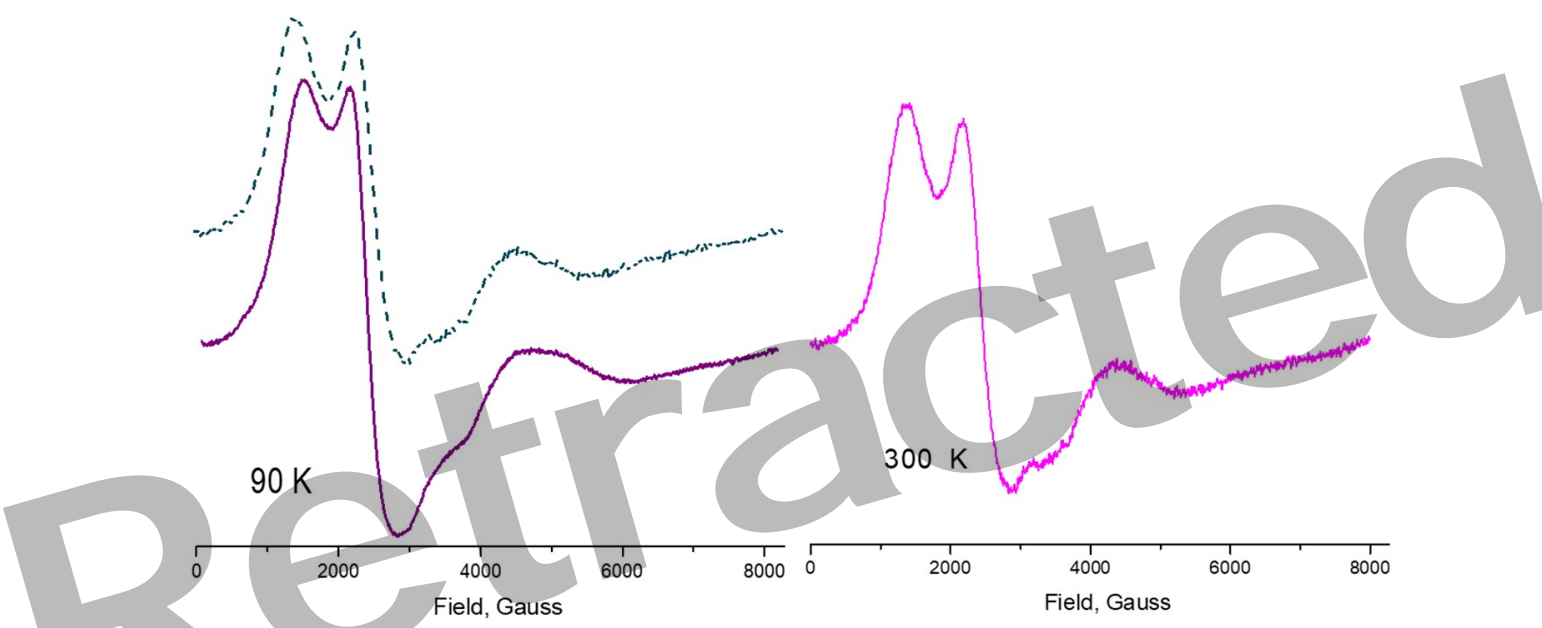

Figure 5. ESR spectra of 1 at $300 \mathrm{~K}$ and $77 \mathrm{~K}$ showing $\mathrm{Mn}(\mathrm{II}), \mathrm{Mn}(\mathrm{III})$ and $\mathrm{Mn}(\mathrm{IV})$ with different spin states. Simulation of the spectrum at $90 \mathrm{~K}$, green dashed line, gave $g$ values of $4.48,1.55$ for $\mathrm{Mn}(\mathrm{IV})$ high spin $s=\frac{3}{2^{\prime}}, 2.76$ characteristic of $\mathrm{Mn}$ (III) low spin $s=1$ and 1.87 which corresponds to Mn(II) low spin $s=\frac{1}{2}$.
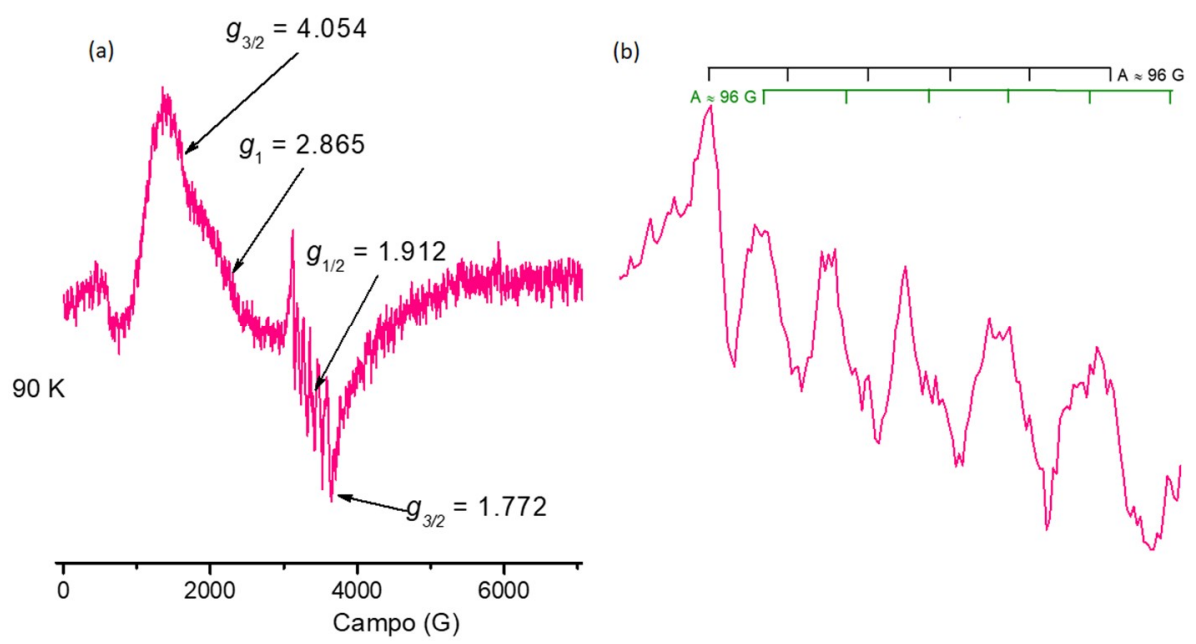

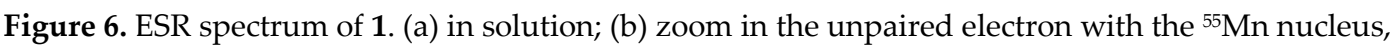
$I_{5 / 2}$, hyperfine interaction and some coupling hyperfine paths and coupling constants values. 
The 1st International Electronic Conference on Crystals (IECC 2018), 21-31 May 2018;

Sciforum Electronic Conference Series, Vol. 1, 2018

Figure 5 shows the ESR spectra of 1 at $300 \mathrm{~K}$ and $80 \mathrm{~K}$ and its simulation. Figure 6 shows the ESR spectrum of 1 in DMSO solution at $90 \mathrm{~K}$, with a zoom into the hyperfine interactions area. Both experiments are consistent with three different oxidation and spin states for the Manganese ions present. 1 contains four Manganese ions with a strong ligand field induced by five oxygen and one nitrogen ligands which stabilize the low spin of $\mathrm{Mn}(\mathrm{II}), s=1 / 2$, and of $\mathrm{Mn}(\mathrm{III}), s=1$, and the high spin of $\mathrm{Mn}(\mathrm{IV}), s=\frac{3}{2}$ [31]. The ESR of $\mathrm{Mn}(\mathrm{II}), \mathrm{Mn}(\mathrm{II})$ and $\mathrm{Mn}(\mathrm{IV})$ ions present in $\mathbf{1}$ is described by spin Hamiltonian for these $3 d^{3}, 3 d^{4}$ and $3 d^{5}$ electronic systems in an axial distorted octahedral coordination sphere, $\widehat{H}=g \beta \vec{H} \cdot \vec{S}+D\left[\vec{S}_{z}^{2}-\frac{1}{3} \vec{S}(\vec{S}+1)\right]-J S_{1} \cdot S_{2}$, where the axial zero-field splitting is $D \ll h v$ at $\mathrm{x}$-band. Coordination compounds with Manganese ions in oxidation state $\mathrm{Mn}(\mathrm{II}), d^{5}$, with low spin, $s=1 / 2$, are less frequent that those of high spin state, and a ${ }^{2} T_{2}$ ground state in a $O_{h}$ symmetry. The ESR of 1 showed Mn(II) species with a $g=187$ value corresponding to low spin (Figure 5), in accord with theoretical and experimental reports as typical values $g<2.0023$ [32]. The $\mathrm{Mn}(\mathrm{III})$ species of 1 showed a signal with $g=2.760$ value. The $\mathrm{Mn}(\mathrm{III})$ has $d^{4}$ electrons and a ${ }^{5} \mathrm{D}$ configuration for its ground sate, which was considered, as a ESR silent system due to the shorter relaxation times or to the large zero-field splitting. However, it has been proposed that for systems with $s>1 / 2$ the magnetic dipole transition is allowed, although not totally, when the Zeeman basis states are mixed by the zero-field Hamiltonian terms. These Zeeman basis state mixtures split the Kramer's doublet of the $| \pm 2\rangle$ and $| \pm 1\rangle$ states into two doublets, each formed by the linear states combination. ESR transition of the $| \pm 1\rangle$ is not totally allowed between the $| \pm 1\rangle$ levels and the $|0\rangle$ level. The $g \sim 2$ values and the shape line for the transitions of $\mathrm{Mn}$ (III) ions are different from Fe(III) ESR signals with its $g=2$ value, complement of other signals at low field [33]. A $d^{3} \mathrm{Mn}(\mathrm{IV})$ ion in an octahedral symmetry has a ground state ${ }^{4} A 2 \mathrm{~g}$ and should show an isotropic resonance on its ESR spectrum with $g \sim 2$ value [34]. Since the four Manganese ions in 1 do not have perfect octahedral geometries, they instead show tetragonal distortion and the spin-orbit interaction is present, the two Kramer's doublets, $= \pm \frac{3}{2} \pm \frac{1}{2}$, are splatted by $2\left(D^{2}+E^{2}\right)$; where $D$ and $E$ are the axial and rhombic zero field parameters, respectively. In accord with the UV-Vis, ESR spectra and the $x$ ray structure the distortion present in 1 is axial, and then $E /{ }_{D}=0$. It is important to note that the zero field split is not observed in the ESR spectra of the solid sample at two temperatures, and we assume that this splitting at zero field is smaller than the $h v=031 \mathrm{~cm}^{-1}$ at $\mathrm{x}$-band. Nevertheless, the ESR spectrum and its simulation (Figure 5) gave $g>4$ and $<<2$ values characteristic of Mn(IV) species, which is identifiable by the transition at higher field since the $g \sim 2$ signal is weak, which has been observed in other works [35].

The Hamiltonian corresponding to ESR spectrum of the solution sample is $\widehat{H}=D\left[\vec{S}_{z}^{2}-\right]+g \beta \vec{H}$. $\vec{S}_{z}-g_{N} \beta_{N} \vec{H} \cdot \hat{I_{z}}+\hat{A \hat{Z}} \cdot \hat{S_{z}}-J \hat{S_{1}} \cdot \hat{S_{2}}$. The ESR spectrum of 1 in solution shows a stronger g 2 signal and the signal with $\mathrm{g} \sim 4$ shows a lower intensity, observing the 55Mn hyperfine interaction on the $\mathrm{g} \sim 2$ signal. The axial parameter $2 D=01 \mathrm{~cm}^{-1} \ll h v=031 \mathrm{~cm}^{-1}$ at $\mathrm{x}$-band is typical of ESR spectra with g 2 dominant signal with respect to this other with $g \sim 4$ [35]. The hyperfine interaction constant values are close to those values for $\mathrm{Mn}(\mathrm{IV}) \quad \mathrm{A} \approx 94-100 \mathrm{G}$ in frozen solution, for $\mathrm{Mn}(\mathrm{III})$ this value of $\mathrm{A}=94$ $\mathrm{G}$, for $\mathrm{Mn}(\mathrm{II}) \mathrm{A}=89 \mathrm{G}$ [35,36]. In the following section the magnetization studies of $\mathbf{1}$ are presented.

\subsection{Magnetic Studies}

$\chi_{M}$ and $\chi_{M}$ TvST plots of 1 are illustrated in Figure 7. The $\chi_{M} T_{300 K}$ value is $3.69 \mathrm{~cm}^{3} \mathrm{~mol}^{-1} \mathrm{~K}$ and corresponds to $S_{T}=2$, which is much lower than $7.87 \mathrm{~cm}^{3} \mathrm{~mol}^{-1} \mathrm{~K}$ with aS ${ }_{T}=7 / 2$, two Mn(II) $s=1 / 2$, on $\mathrm{Mn} \quad$ (III)s $=1$ on $\mathrm{Mn} \quad(\mathrm{N}) \mathrm{s}=3 / 2$, if these did not interact magnetically. When the temperature decreased, the $\chi_{M} T_{65} \mathrm{~K}^{\mathrm{val}}$ uencreasa $504 \quad \mathrm{~cm}^{3} \mathrm{~mol}^{-1} \mathrm{~K}$, and at lower temperature the $\chi_{M} T_{446 \mathrm{~K}} \quad$ value was of $4.46 \mathrm{~cm}^{3} \mathrm{~mol}^{-1} \mathrm{~K}$. At $65 \mathrm{~K}$ there is a change of magnetic order and in a temperature range of 12 degrees the $\chi_{M} T_{524 K}$ val udecreased47 $\mathrm{cm}^{3} \mathrm{~mol}^{-1}$; although the 
response of the spins to the magnetic field at lower temperature changes when the restriction in the degrees of freedom of the spins is major, showing a new magnetic structure [37].

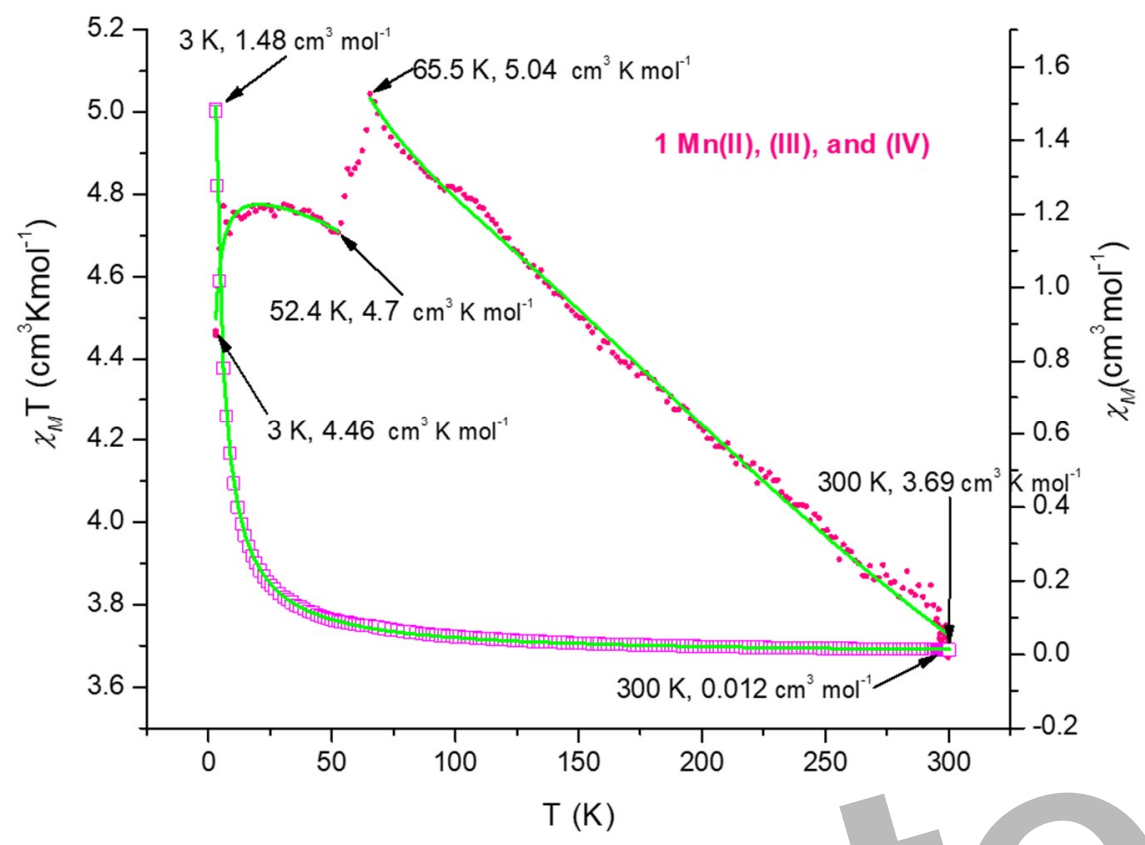

Figure 7. Magnetic susceptibility dependence on the temperature for 1 . The green solid lines correspond to the best fit using eq 3 . The correlation coefficients values were: for total data $\chi_{M} v S T r^{2}=0.9999$, for $\chi_{M} \operatorname{TvST}(300-655 K) \quad r^{2}=090$ and $T(655-3 K) \quad$ section of $r^{2}=099$.

The Heisenberg Hamiltonian, eq 2, was proposed to fit the susceptibility data vs temperature, considering the oxidation state and spin state of each Manganese ion of $\mathbf{1}$, and that the exchange interaction constants are as in Figure 8.

$$
H=-2 J_{1}\left(S_{1} \cdot S_{2}\right)-2 J_{2}\left(S_{2} \cdot S_{3}\right)
$$

where $J_{1}$, and $J_{2}$ are the exchange magnetic constants and $S_{i}$ are the spin operators [38].

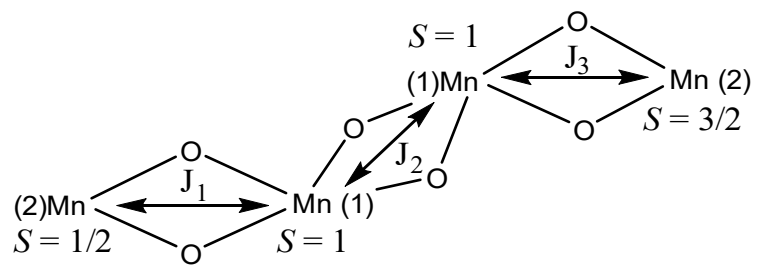

Figure 8. Structural arrangement for $\left[\mathrm{M}_{4} \mathrm{O}_{6}\right]$ and the exchange magnetic constant of $\mathbf{1}$ making ${ }_{1}=$ $J_{3} \neq J_{2}$.

Considering that these bulk magnetic quantifications are less fine sensitive and do not differentiate neither oxidation nor spin states of the Manganese ions the coupling constants $J$ were proposed as $j_{1}=J_{3} \neq J_{2}$. Taking these considerations into account, the best data adjustment was made by two sections with the modified Bleany-Bowers equation (eq 3) [39], giving the following values: $J_{1}=J_{3}=-11 \mathrm{~mm}^{-1}, J_{2}=-164 \mathrm{~cm}^{-1}$, with a $g=2$ value.

$$
\chi_{M}=\frac{N \beta^{2} g^{2}}{3(T-\theta)}\left[1+\frac{1}{3} \exp \left(-\frac{2 J}{k T}\right)\right]^{-1}(1-\rho)+\frac{\left(N \beta^{2} g^{2}\right) \rho}{4 k T}+N \alpha
$$


The $J^{\prime} s<0$ values are characteristic of exchange antiferromagnetic interactions, and returning to the ESR area ratio only small spin population remains directed with the field magnetic. The oxobridges angles $>90^{\circ}$ in the structure of $\mathbf{1}$ are consistent with an exchange antiferromagnetic interaction. It is important to note that to quantify the $J$ values, the oxidation states of Manganese ions are considered as $+2,+3,+3,+4$, respectively. Additionally, the two negative charges of the nitrate groups might be on the Manganese ions labeled as outer, or only on one of them. Similar to $x$ ray diffraction, this bulk quantification does not detect the fine tuning magnetic behavior, which is observed by ESR spectrometry. The magnetic response points towards that at $65.5 \mathrm{~K}$ and below the oxo-bridges angles will take values $\gg 90^{\circ}$ and the Mn1 ions will be aligned with the other two outer ions, switching towards a stronger antiferromagnetic coupling with a modified magnetic order, electronic, and spatial arrangement.

\subsection{Computational Calculations}

An optimization of $\mathbf{1}$ at the crystallographic initial coordinates proved to reproduce the distance pattern of four distances shorter than $2.1 \AA$ forming a plane and two axial distances larger than $2.1 \AA$ (Table 6). This arrangement showed a spin density on all four Mn cation consistent with a $3 \mathrm{~d}^{4} \mathrm{Mn}^{\mathrm{III}}$ (Table 7). Since this interpretation was inconsistent with the ESR results, five more models were explored in order to establish which model could produce a mixture of $\mathrm{Mn}^{\mathrm{II}}$ and $\mathrm{Mn}^{\mathrm{IV}}$.

Table 6. Geometric parameters of the first coordination sphere of Mn in the models optimized with B3LYP/6-31g(d)/LANL2DZ. Values in Å.

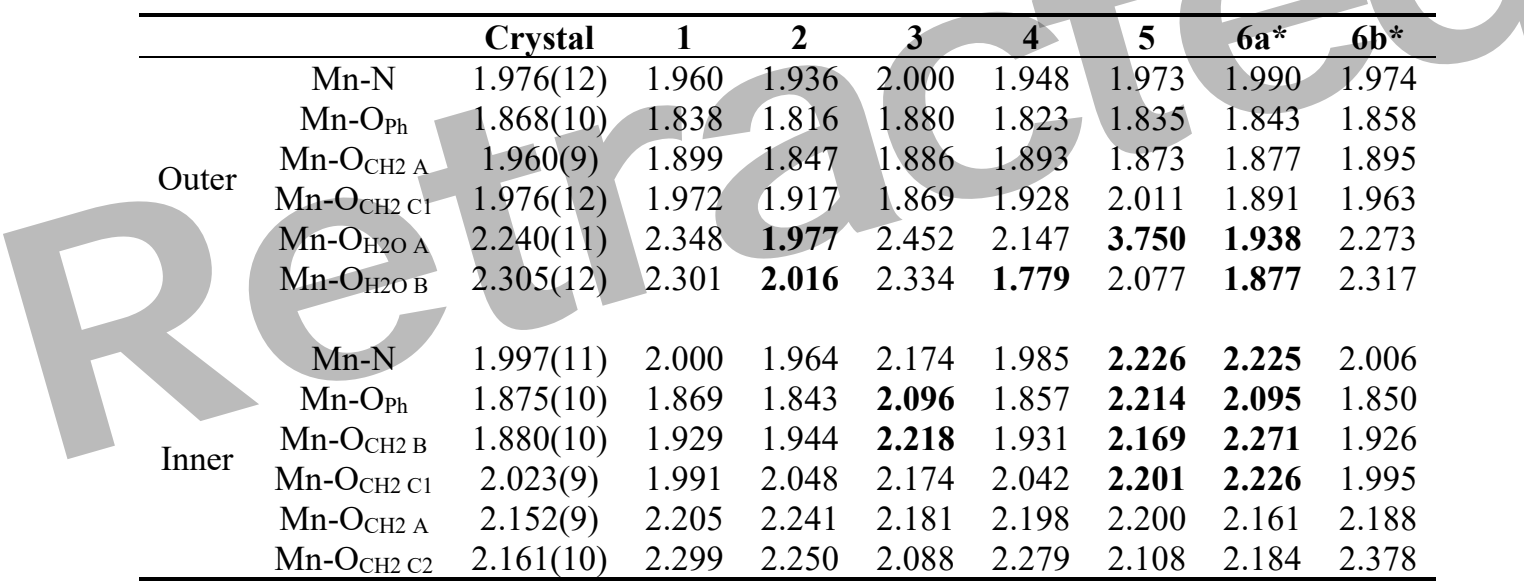

* Values $\mathbf{a}$ and $\mathbf{b}$ correspond to different sides since $\mathbf{6}$ has no $C i$ symmetry. Values in black correspond to Mn where the change of the distances is more than $10 \%$ with respect to 1 .

The first option was a two electron disproportion of the two $\mathbf{1}$ molecules, which would in turn produce a double oxidized species, $\left[\mathrm{Mn}^{\mathrm{III}}{ }_{2} \mathrm{Mn}^{\mathrm{IV}}{ }_{2}\left(\mathrm{H}_{2} \mathrm{~L}\right)_{2}(\mathrm{HL})_{2}\left(\mathrm{H}_{2} \mathrm{O}\right)_{4}\right]^{4+}$, 2. It would also produce a double reduced species $\left[\mathrm{Mn}^{\mathrm{II}_{2}} \mathrm{Mn}_{2} \mathrm{II}_{2}\left(\mathrm{H}_{2} \mathrm{~L}\right)_{2}(\mathrm{HL})_{2}\left(\mathrm{H}_{2} \mathrm{O}\right)_{4}\right]$, 3. These two molecules show different modifications of the first coordination sphere distances, shortening the axial water molecules distances in the case of 2 and elongating four $\mathrm{Mn}-\mathrm{X}$ in the case of $\mathbf{3}$. These distance modifications correspond to changes in the Mulliken spin densities (Table 7) to the formation of two $\mathrm{Mn}^{\mathrm{IV}}$ in the outer $\mathrm{Mn}$ cation in the case of 2 and two inner $\mathrm{Mn}^{\mathrm{II}}$ in the case of 3 . The free energy difference at B3LYP/6-31g+(d)/LANL2DZ ( $\Delta$ Gв3Lур) for the process is $274.6 \mathrm{kcal} / \mathrm{mol}$, suggesting this process is not possible at room temperature or lower.

Values in black correspond to Mn where the change of the spin population varies more than 0.3 electrons and correspond to the gain or loss of one electron.

The second option corresponds to the transfer of two hydrogen atoms from one 1 molecule to other 1 molecule. In this scenario $\left[\mathrm{Mn}_{2}^{\mathrm{III}} \quad \mathrm{Mn}^{\mathrm{IV}_{2}}\left(\mathrm{H}_{2} \mathrm{~L}\right)_{4}\left(\mathrm{H}_{2} \mathrm{O}\right)_{4}\right]^{2+}, 4$ and $\left[\mathrm{Mn}^{\mathrm{III}_{2}} \mathrm{Mn}_{2}^{\mathrm{II}_{2}}\right.$ $\left.\left(\mathrm{H}_{2} \mathrm{~L}\right)_{2}(\mathrm{HL})_{2}\left(\mathrm{H}_{2} \mathrm{O}\right)_{2}(\mathrm{OH})_{2}\right]^{2+}, 5$ would be produced. Models 4 and $\mathbf{5}$ produce similar changes to the 
The 1st International Electronic Conference on Crystals (IECC 2018), 21-31 May 2018;

Sciforum Electronic Conference Series, Vol. 1, 2018

Mn-X distances and the Mülliken spin densities corresponding to oxidation of the outer Mn and reduction of the inner $\mathrm{Mn}$. The $\Delta$ Gвзцир is $62.9 \mathrm{kcal} / \mathrm{mol}$, which is considerably lower in energy than the process to obtain 2 and 3 but still not possible at room temperature.

Table 7. Mulliken spin populations of Mn atoms in the models considered computationally.

\begin{tabular}{|c|c|c|c|c|c|c|c|}
\hline & Mn type & 1 & 2 & 3 & 4 & 5 & $6^{*}$ \\
\hline \multirow[t]{2}{*}{$\mathrm{PBE} / 631 \mathrm{~g}$} & Inner & 3.837 & 3.804 & 4.390 & 3.830 & 4.533 & $\begin{array}{c}\mathbf{4 . 6 2 4} \\
(3.884)\end{array}$ \\
\hline & Outer & 3.844 & 2.743 & 4.063 & 2.817 & 3.995 & $\begin{array}{c}\mathbf{3 . 0 4 1} \\
(3.860) \\
\end{array}$ \\
\hline \multirow[t]{2}{*}{ B3LYP/631g(d) } & Inner & 3.850 & 3.848 & 4.745 & 3.856 & 4.781 & $\begin{array}{c}\mathbf{4 . 7 9 7} \\
(3.858)\end{array}$ \\
\hline & Outer & 3.832 & 2.546 & 3.840 & 2.850 & 3.785 & $\begin{array}{c}2.906 \\
(3.871) \\
\end{array}$ \\
\hline \multirow[t]{2}{*}{ B3LYP/631g+(d) } & Inner & 4.663 & 4.709 & 5.283 & 4.637 & 5.366 & $\begin{array}{c}\mathbf{5 . 3 2 7} \\
(4.509)\end{array}$ \\
\hline & Outer & 4.270 & 2.735 & 4.245 & 3.096 & 4.042 & $\begin{array}{r}\mathbf{3 . 1 3 2} \\
(4.280) \\
\end{array}$ \\
\hline
\end{tabular}

*Values in parenthesis are from different sides since 6 has no $C i$ symmetry.

A third model was attempted with four extra water molecules, [Mn ${ }^{\mathrm{III}_{2}} \mathrm{Mn}^{\mathrm{II}} \mathrm{Mn}^{\mathrm{IV}}$ $\left.\left(\mathrm{H}_{2} \mathrm{~L}\right)_{2}(\mathrm{HL})_{2}\left(\mathrm{H}_{2} \mathrm{O}\right)_{8}\right]^{2+}, 6$. The justification for this model comes from the observation that artificially imposed $\mathrm{Mn}-\mathrm{X}$ distances corresponding to outer $\mathrm{Mn}$ in $\mathbf{2}$ and inner $\mathrm{Mn}$ in $\mathbf{3}$ induced the oxidation states consistent with the ESR results but introduced great instability to the all molecule and eventually a restriction-free optimization produced $\mathbf{1}$ again. To diminish these instabilities, four water molecules were added. The resulting molecule could not be optimized to a minimum with a $\mathrm{Ci}$ symmetry. However, this asymmetry induced the observation of the three oxidation states of $\mathrm{Mn}$ in the same molecule. The distances and Mülliken spin densities are consistent with this explanation. The $\Delta \mathrm{Gвзцир} \mathrm{for} \mathrm{the} \mathrm{reaction} \mathrm{where} \mathrm{four} \mathrm{water} \mathrm{molecules} \mathrm{are} \mathrm{included} \mathrm{in} \mathrm{the} \mathrm{complex} \mathrm{is} 23.3 \mathrm{kcal} / \mathrm{mol}$, which is still lower in energy than the two other process considered and the most probable explanation from an energy point of view. 

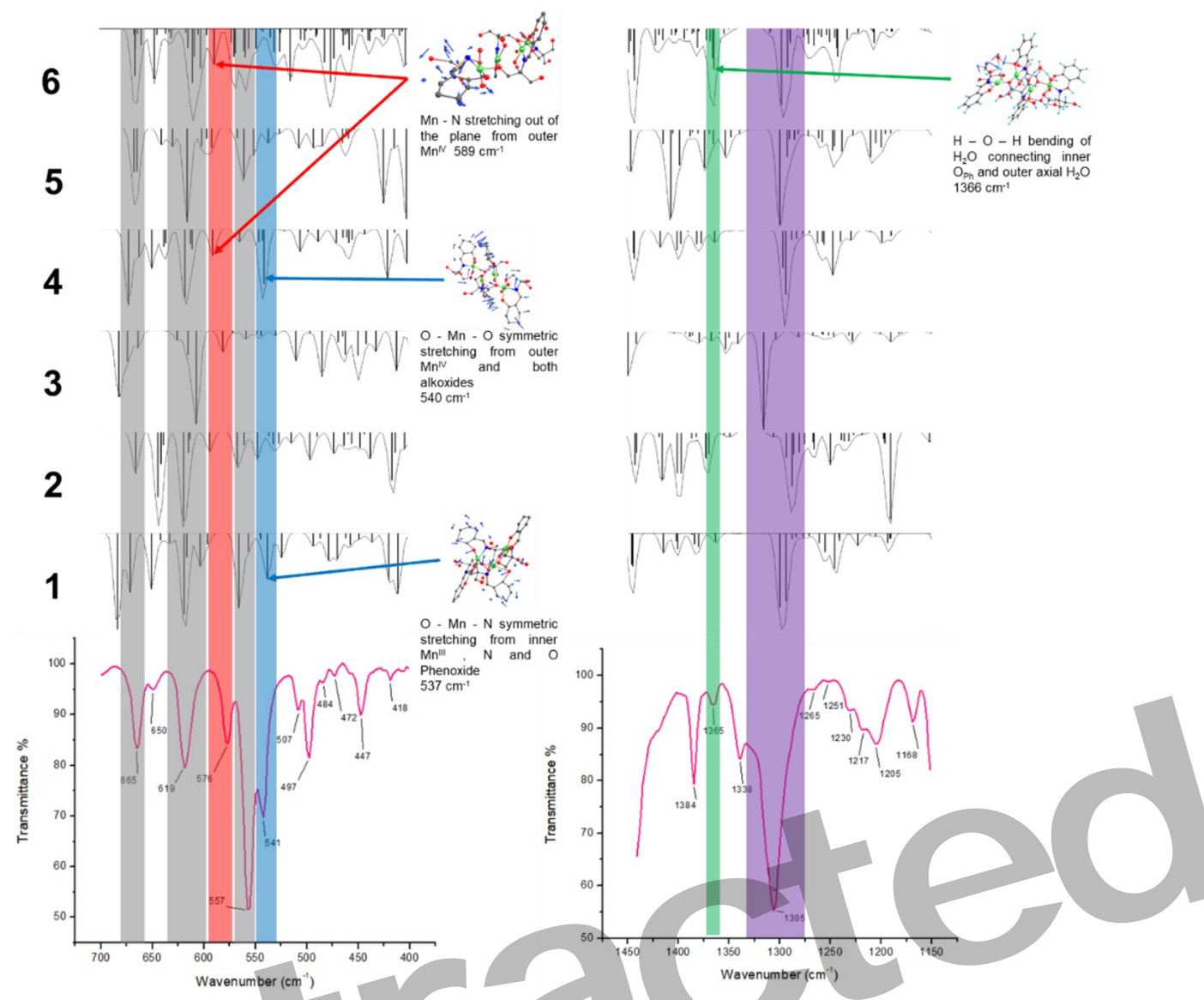

Figure 9. Comparison of experimental (bottom) and theoretical (model compounds 1-6) IR spectra.

Another tool we used to sustain that model 6 is responsible for the ESR signals are the IR vibrational modes. Modifications in the oxidation state of the Mn cations may increase/decrease the energy of certain vibrational modes. We focused our attention to $\mathrm{Mn}-\mathrm{X}$ stretching modes and phenoxide $\mathrm{C}-\mathrm{O}$ stretching modes. From DFT calculations some of these vibrational modes could be assigned and compared with experimental IR spectra. The results are shown in figure 9.

From Figure 9 it can be noticed that the bands at 665, 619 and $557 \mathrm{~cm}^{-1}$ are common to all the models and would not help to discriminate among them. An important band is $576 \mathrm{~cm}^{-1}$, which is not present in 1, but it is in 4 and 6 . The band at $541 \mathrm{~cm}^{-1}$ is weakly present in $\mathbf{1}$, but is strongly present in 4 and corresponds to a vibrational mode that includes $\mathrm{Mn}^{\mathrm{IV}}$. Regarding the band at $1305 \mathrm{~cm}^{-1}$, it distinctively corresponds to the $\mathrm{C}$ - Oph stretching vibration coordinated to different Mn cations. It can be noticed that a vibrational mode from a single model, as is the case of $\mathbf{1}$, would not account for the broadening of that band. Furthermore, the charge changes in the Mn cations coordinating the OPh would produce the shift observed in those bands. It would rise the energy of C - Oph stretching mode when $\mathrm{Mn}^{\mathrm{IV}}$ was coordinated and lower the energy in the case of $\mathrm{Mn}^{\mathrm{II}}$. It is worth mentioning that the protonation state and hydrogen bond networks of Oph also play a significant role in the energy of this vibrational mode, in particular in model 6 where all vibrational modes are expected to be present. One particular marker that is distinctive of model 6 is the signal at $1365 \mathrm{~cm}^{-1}$. This signal is barely present in the experimental spectra and only active in model 6. It corresponds to a water bending from the extra water molecules. This observation and the values for the free energy variation suggest that model 6 is the responsible for the ESR behavior. 
The 1st International Electronic Conference on Crystals (IECC 2018), 21-31 May 2018; Sciforum Electronic Conference Series, Vol. 1, 2018

\section{Conclusions}

A different set of reaction conditions where temperature, reaction time and stoichiometry were varied consistently produced 1 . The electronic, experimental, and theoretical studies were fundamental to reconcile the crystal structure with the spectroscopic measurements obtained. The subtle structural changes caused by intramolecular electron transfer can only be established by ESR studies at different temperatures, presented as snapshots of the structural conformations. The theoretical calculations exploring oxidation and spin states on the different Manganese ions have proven to be an important tool to correlate the experimental results.

Acknowledgments: H.V.L. Acknowledges the financial support from CONACyT postdoctoral fellowship. We thank the Laboratorio Nacional de Supercomputo del Sureste (LNS), BUAP, Mexico, for providing computing resources to perform theoretical calculations. This work was financed from BUAP by Vicerrectoría de Investigación y Estudios de Posgrado Projects: REOY-NAT16-G, REOYNAT17-G and HEAS NAT-17. Projects by Redes Temáticas PRODEP: Química de Coordinación con Aplicación al Magnetismo y Catálisis Homogénea 2015-2016 and PTC-463. CA-261-BUAP. As well as CONACyT scholarship for Cándida Pastor Ramírez.

\section{References}

1. (a) Baibich, M.N.; Broto, J.M.; Fert, A.; Nguyen van Dau, F.; Petroff, F.; Etienne, P.; Creuzert, G.; Friedrich, A.; Chazelas, J. Phys. Rev. Lett. 1988, 61, 2472-2475; (b) Hellman, F.; Tran, M.Q.; Gebala, A.E.; Wilcox, E.M.; Dynes, R.C. Phys. Rev. Lett. 1996, 77, 4652-4655; (c) Rao, C.N.R.; Cheetham, A.K. Science 1996, 272, 369-370; (d) Subramanian, M.A.; Toby, B.H.; Ramirez, A.P.; Marshall, W.J.; Sleight, A.W.; Kwei, G.H. Science 1996, 273, 81-84; (e) Ramirez, A.P.; Cava, R.J.; Krajewski, J. Nature 1997, 386, 156-159; (f) Chan, J.Y.; Kauzlarich, S.M.; Klavins, P.; Shelton, R.N.; Webb, D.J. Phys. Rev. 1998, 57, R8103-R8106; (g) Kim, H.; Klavins, P.; Kauzlarich, S.M. Chem. Mater. 2002, 14, 2308-2316.

2. Dharmalingam, S.; Kwanghyo, S.; Ha.Jin, L.; Key, T.P.; Zeehoon, J.; Byoung, J.S.; Sungho, Y. Polyhedron 2013, 50, 339-344.

3. (a) Gatteschi, D.; Sessoli, R. Angew. Chem., Int. Ed. 2003, 42, 268-297; (b) Ritter, S.K. Chem. Eng. News, 2004, 82, 29-32; (c) Aubin, S.M.J.; Dilley, N.R.; Wemple, M.W.; Maple, M.B.; Christou, G.; Hendrickson, D.N. J. Am. Chem. Soc. 1998, 120, 839-840.

4. Li, B.-W.; Zhou, Y.-L.; Chen, Q.; Zeng, M.-H. Polyhedron 2010, 29, 148-153.

5. (a) Payne, A.C.; Olmstead, M.M.; Kauzlarich, S.M.; Webb, D.J. Chem. Mater. 2001, 13, 1398-1406; (b) Kim, H.; Olmstead, M.M.; Klavins, P.; Webb, D.J.; Kauzlarich, S.M. Chem. Mater. 2002, 14, 3382-3390; (c) Jiang, J.; Olmstead, M.M.; Kauzlarich, S.M.; Lee, H.O.; Klavins, P.; Fisk, Z. Inorg. Chem. 2005, 44, 5322-5327.

6. (a) Pecoraro, V.L.; Hsieh, W.-Y. In Manganese and Its Role in Biological Processes; Sigel, A., Sigel, H., Eds.; Marcel Dekker: New York, NY, USA, 2000, 37, 429; (b) Carrell, T.G.; Tyryshkin, A.M.; Dismukes, G.C. J. Biol. Inorg. Chem. 2002, 7, 2-22; (c) Kok, B.; Forbush, B.; McGloid, M. Photochem. Photobiol. 1970, 11, 457-475.

7. Yachandra, V.K.; Guiles, R.D.; McDermott, A.E.; Britt, R.D.; Cole, J.; Dexheimer, S.L.; Sauer, K.; Klein, M.P. J. Phys. Colloq. 1986, 47, C8/1121-C8/1128.

8. Chan, M.K.; Armstrong, W.H. J. Am. Chem. Soc. 1990, 112, 4985-4986.

9. Liu, D.; Zhou, Q.; Chen, Y.; Yang, F.; Yu, Y.; Shi, Z.; Feng, S. Dalton Trans. 2010, 39, 5504-5508.

10. Stoe \& Cie. X-AREA and X-RED32, Stoe \& Cie, Darmstadt, Germany, 2015.

11. (a) Sheldrick, G.M. (2008); (b) Acta Cryst. A64, 112-122; (c) Sheldrick, G.M. (2015a); (d) Acta Cryst. A71, 38; (e) Sheldrick, G.M. (2015b); (f) Acta Cryst. C71, 3-8.

12. (a) Perdew, J.P.; Burke, K.; Ernzerhof, M. Phys. Rev. Lett. 1996, 77, 3865-3868; (b) Perdew, J.P.; Burke, K.; Ernzerhof Phys. Rev. Lett. 1997, 78, 1396-1396.

13. Hehre, W.J.; Ditchfield, R.; Pople, J.A. J. Chem. Phys. 1972, 56, 2257-2261; (b) Rassolov Vitaly, A.; Ratner Mark, A.; Pople John, A.; Redfern Paul, C.; Curtiss Larry, A. J. Comput. Chem. 2001, 22, 976-984.

14. Becke, A.D. J. Chem. Phys. 1993, 98, 5648-5652.

15. Hay, P.J.; Wadt, W.R. J. Chem. Phys. 1985, 82, 270-283.

16. Shriver, D.F.; Atkins, P.W. Inorganic Chemistry, 3rd ed.; W. H. Freeman and Co.: New York, USA, 1999, 763. 
The 1st International Electronic Conference on Crystals (IECC 2018), 21-31 May 2018;

Sciforum Electronic Conference Series, Vol. 1, 2018

17. Zhang, C.; Zu, P.; Wu, D.; and Yu K. J. Chem. Res. (S). 2000, 402-403.

18. Wu, Q; Shi, Q.; Li, Y.-G.; Wang, E.-B. J. Coord. Chem. 2008, 61, 3080-3091.

19. (a) Liu, W.; Thorp, H.H. Inorg. Chem. 1993, 32, 4102-4105; (b) Altermatt, D.; Brown, I.D. Acta Cryst. 1985, B41, 240-244.

20. Taguchi, T.; Stone, L.K; Gupta, R; Kaiser-Lassalle, B.; Yano, J.; Hendrich, P.M.; Borovik, A.S. Chem. Sci. 2014, 5, 3064-3071.

21. Alvarez, S; Avnir, D.; Llunell, M.; Pinsky, M. New J. Chem. 2002, 26, 996-1009.

22. (a) Dunitz, J.D.; Orgel, L.E. J. Phys. Chem. Solids; Pergamon Press: New York, NY, USA, 1957, 3, 20-29; (b) OriginLab Corporation: Northampton, MA, USA. 2017.

23. (a) Tiannan, Y.; Shan, Li.; Xueyan, W.; Miao, X.; Xiao, W.; Kaixue, W.; Hongliang, B.; Jianqiang, W.; Jiesheng, Ch. J. Mater. Chem. C, 2013, 1, 4327-4333; (b) Cotton, F.A.; Wilkinson, G. Advanced in Inorganic Chemistry, A Comprehensive Text, 4th ed; John Wiley and Sons, New York, NY, USA, 1980, 1396.

24. Ferguson, A.; Parkin, A.; Sanchez-Benitez, J.; Kamenev, K.; Wernsdorfer, W.; Murrie, M. Chem. Commun. 2007, 33, 3473-3475.

25. (a) Romero, I.; Collomb, M.-N.; Deronzier, A.; Llobet, A.; Perret, E.; Pécaut, J.; Le Pape, L.; Latour, J.-M. Eur. J. Inorg. Chem. 2001, 69-72; (b) Ferguson, J.; Guggenheim. H.J.; Tanabe,Y. J. Phys. Soc. Jpn. 1966, 21, 692-704; (c) Muñoz, A.; Casáis, M.T.; Alonso, J.A.; Martínez-Lope, M.J.; Martínez, J.L.; Fernández-Díaz, M.T. Inorg. Chem. 2001, 40, 1020-1028.

26. Mukhopadhyay, S.; Staples, R.J.; Armstrong, W.H. Chem. Commun. 2002, 864-865.

27. Singh, M.K.; Kar, N.K.; Lal, R.A. J. Coord. Chem. 2008, 61, 3158-3171.

28. (a) Kulzer, F.; Orrit, M. Annu. Rev. Phys. Chem. 2004, 55, 585-611; (b) Moerner, W.E.; Kador, L. Phys. Rev. Lett. 1989, 62, 2535-2538.

29. Bloembergen, N.; Purcell, E.M.; Pound, R.V. Phys. Rev. 1948, 73, 679-712.

30. (a) Mabbs, F.E.; Collison, D. Electron Paramagnetic Resonance of d Transition Metal Compounds; Chem. Soc. Rev. 1993, 1-12; (b) Drago, R.S. Physical Methods in Chemistry, 2nd ed.; Saunders College Publishing: Ft. Worth, TX, USA, 1992, 745.

31. (a) Azamat, D.V.; Dejneka, A.; Lancok, J.; Trepakov, V.A.; Jastrabik, L.; Badalyan, A.G. J. Appl. Phys. 2012, 111, 104119-1-104119-6; (b) Ramírez D.R., Zamorano R.U. Pérez O.M. Solid State Commun. 2001, 118, $371-$ 376; (c) Syiemlieh, I.; Kumar, A.; Kurbah, S.D.; Arjune, K. De; Lal, R,A. J. Mol. Struct. 2018, 1151, 343-352.

32. (a) Gross, R.; Wolfang, K. J. Chem Soc. Faraday Trans. 1987, 83, 3549-3564; (b) Dexheimer, S.L.; Gohdes, J.W.; Chan, M.K.; Hagen, K.S.; Armstrong, W.H.; Klein, M.P. J. Am Chem. Soc. 1989, 11, 8923-8925.

33. Abragam, A.; Bleany, B. Electron Paramangnetic Resonance of Transitions Metals Ions, Clarendon Press: Oxford, UK, 1970, 209-211.

34. Singh, M.K.; Kar, N.K.; Lal, R.A. J. Coord. Chem. 2009, 62, 1677-1689.

35. (a) Pal, S.; Ghosh, P.; Chakravorty, A. Inorg. Chem. 1985, 24, 3704-3706; (b) Bukovec, P.; Hoppe, R. J. Fluor. Chem. 1983, 23, 579-587; (c) Pedersen, E.; Toftlund, H. Inorg. Chem. 1974, 13, 1603-1612.

36. (a) Krivokapic, I.; Noble, Ch.; Klitgaard, S.; Tregenna-Piggott, P.; Weihe, H.; Barra, A.-L. Angew. Chem. 2005, 117, 3679-3682; (b) Rotlevi, E.; Eaton, D.R. Canadian J. Chem. 1970, 48, 1073-1077; (c) Sheats, J.E.; Czernuszewics, R.S.; Dismikes, G.Ch.; Rehingold, A.L.; Petrouleas, V.; Stubbe, J.A.; Armstrong, W.H.; Beer, R.H.; Lippard, S.J. J. Am. Chem. Soc. 1987, 109, 1435-1444.

37. Milios, J.C.; Piligkos, S.; Bell, R.A.; Laye, H.R.; Teat, J.S.; Vicente, R.; McInnes, E.; Escuer, A.; Perlepes, P. S.; Winpenny, P.E.R. Inorg. Chem. Commun. 2006, 9, 638-641.

38. Yoo, J.; Brechin, E.; Yamaguchi, A.; Nakano, M.; Huffman, C.J.; Maniero, L.A.; Brunel, L.C.; Awaga, K.; Ishimoto, H.; Christou, G.; Hendrickson, D. Inorg. Chem. 2000, 39, 3615-3623.

39. Bleaney, B.; Bowers D.K. Proc. R. Soc. Lond. A 1952, 214, 451-465.

(C) 2018 by the authors; licensee MDPI, Basel, Switzerland. This article is an open access article distributed under the terms and conditions of the Creative Commons by Attribution (CC-BY) license (http://creativecommons.org/licenses/by/4.0/). 